\title{
The Effect of Clozapine on Plasma Norepinephrine: Relationship to Clinical Efficacy
}

Alan Breier, M.D., Robert W. Buchanan, M.D., Royce W. Waltrip II, M.D., Samuel Listwak, Courtney Holmes, C.M.T., and David S. Goldstein, M.D., Ph.D.

Clozapine is an atypical neuroleptic medication with superior efficacy to conventional antipsychotic agents for patients with chronic, symptomatic schizophrenia. Neurochemical characteristics that distinguish clozapine from other neuroleptics and contribute to its differential efficacy are not known. We assessed the effects of clozapine on plasma levels of norepinephrine (NE) in a double-blind, parallel groups comparison of clozapine $(\mathrm{n}=11)$ and haloperidol $(\mathrm{n}=15)$ in chronic schizophrenic outpatients who had been previously treated with fluphenazine. Simultaneous measurements were obtained for plasma levels of the catecholamine precursor dopa, the dopamine metabolite dihydroxyphenylacetic acid (DOPAC), the NE metabolite 3,4-dihydroxyphenylglycol (DHPG), adrenocorticotropin (ACTH), cortisol, and hemodynamic parameters.

Clozapine produced marked increases (471\%) in plasma
NE levels, whereas haloperidol had no significant effects on plasma NE levels. Clozapine also increased dopa and tended to increase DOPAC levels, without effects on DHPG, ACTH, or cortisol levels and without consistent changes in blood pressure. Across patients, the magnitude of clozapine-induced increments in plasma $N E$ levels was positively related to improvement in positive symptoms and global symptomatology and was unrelated to the occurrence of extrapyramidal symptoms. The results suggest that clozapine differs importantly from other neuroleptics in increasing plasma NE levels, with the peripheral noradrenergic stimulation related to its superior efficacy profile. The unchanged DHPG levels and absence of hypertension suggest a more complex mechanism of action of clozapine than heightened NE release alone. [Neuropsychopharmacology 10:1-7, 1994]
KEY WORDS: Clozapine; Plasma norepinephrine; Schizophrenia; Clinical efficacy; $\alpha_{1}$-Receptor, Mechanism of action; Catecholamines
From the Maryland Psychiatric Research Center (AB, RWB, RWW), Baltimore; Experimental Therapeutics Branch (AB), and Clinical Psychobiology Branch (SL), National Institute of Mental Health; Clinical Neuroscience Branch (CH, DSG), National Institute of Neurological Disorders and Stroke, National Institutes of Health, Bethesda, Maryland.

Addresscorrespondence to: Alan Breier, M.D., National Institutes of Health, NIMH, Experimental Therapeutics Branch, 9000 Rockville Pike, Building 10 Room 4N212, Bethesda, Maryland 20892.

Received April 29, 1993; revised August 5, 1993; accepted August $12,1993$.
Clozapine is an atypical neuroleptic with superior antipsychotic efficacy in patients with schizophrenia who are refractory to conventional treatments (Kane et al., 1988; Meltzer et al., 1990; Pickar et al. 1992; Breier et al. 1993). Intensive investigational efforts are aimed at identifying the biochemical characteristics of clozapine that produce its superior efficacy. This study reports that clozapine produces a striking peripheral neurochemical profile, including very high plasma levels of norepinephrine (NE), and that this profile is related to clozapine's clinically beneficial effects.

The neurochemical effects of clozapine differ in several ways from those of conventional neuroleptics. These properties include a high ratio of serotonergic $5-\mathrm{HT}_{2}$ receptor to dopamine $\mathrm{D}_{2}$ receptor binding (Melt- 
zer 1989) and relatively high affınity for the newly cloned $\mathrm{D}_{4}$ receptor (Van Tol et al. 1991). Clozapine also has higher affinity for noradrenergic $\alpha_{1^{-}}$and $\alpha_{2-}$ adrenoceptors than do many conventional neuroleptics (Baldessarini and Frankenberg 1991; Cohen and Lipinski 1986; Richelson and Nelson 1984). In rats, clozapine increases the activity of noradrenergic neurons and noradrenergic turnover (Baldessarini et al., 1992). Clinical studies have demonstrated that chronic clozapine treatment increases cerebrospinal fluid (CSF) and plasma NE levels, whereas conventional neuroleptics do not (Pickar et al., 1992; Liberman et al., 1991; Ackenheil 1989). No study to date has reported a significant relationship between clozapine's noradrenergic effects and its superior clinical efficacy.

The present study used a double-blind, parallel groups design to compare the effects of clozapine with those of haloperidol on plasma levels of NE in patients who had been previously treated with fluphenazine. Plasma levels of dopa, the precursor of the catecholamines; dihydroxyphenylacetic acid (DOPAC), a dopamine metabolite; 3,4-dihydroxyphenylglycol (DHPG), the intraneuronal metabolite of $\mathrm{NE}$; and hemodynamic parameters were also measured. These indices reflect specific aspects of NE synthesis and metabolism and, therefore, provide information about mechanisms of changes in NE levels. Plasma cortisol and adrenocorticotropin (ACTH) were measured to assess the specificity of noradrenergic effects. Relationships between clozapine's effects on plasma NE levels and symptom ratings were examined.

\section{MATERIALS AND METHODS}

\section{Subjects}

Twenty-six outpatients of the Maryland Psychiatric Research Center participated in a double-blind, parallel groups efficacy study of clozapine compared to haloperidol for chronic schizophrenia. The complete admission criteria and results of the efficacy study have been reported previously (Breier et al. 1993). In brief, patients who met DSM III-R (American Psychiatric Association) criteria for chronic schizophrenia as determined by a Structured Clinical Interview for DSM III R (SCID) (Spitzer et al. 1989) and by a best-estimate diagnostic conference led by two research psychiatrists were included in the study. Patients with concurrent drug abuse, alcoholism, organic brain disorders, mental retardation, or a medical condition in which clozapine is contraindicated were excluded from the study of the patients. The age range of the patients was 18 to 55 years. In addition, patients had a history of partial responsiveness to conventional neuroleptics and had residual positive and/or negative symptoms at the time of admission to the study. Eleven patients were assigned randomly to
Table 1. Demographic and Clinical Characteristics $^{a}$ of 26 Patients

\begin{tabular}{lcc}
\hline \multicolumn{1}{c}{ Patient Characteristic } & $\begin{array}{c}\text { Clozapine } \\
(\boldsymbol{n}=\mathbf{1 1})\end{array}$ & $\begin{array}{c}\text { Haloperidol } \\
(\boldsymbol{n}=\mathbf{1 5})\end{array}$ \\
\hline Age $(\mathrm{yr})$ & $34.7 \pm 5.9$ & $36.8 \pm 9.3$ \\
Sex $(\mathrm{M} / \mathrm{F})$ & $7 / 4$ & $13 / 2$ \\
Race $(\mathrm{W} / \mathrm{B})$ & $7 / 4$ & $10 / 5$ \\
SES & $4 \pm 1$ & $4 \pm 1$ \\
Age of onset (yrs) & $17.3 \pm 5.75$ & $22.7 \pm 5.69$ \\
Duration of illness (yrs) & $17.4 \pm 5.9$ & $14.2 \pm 7.1$ \\
No. of hospitalizations & $6.0 \pm 7$ & $9.6 \pm 11$ \\
BPRS positive symptom score & & \\
$\quad$ Baseline & $13.6 \pm 4.6$ & $13.4 \pm 4.7$ \\
$\quad$ 10 weeks & $11.3 \pm 5.14$ & $12.4 \pm 4.2$ \\
BPRS total score & & \\
$\quad$ Baseline & $36.7 \pm 9.0$ & $38.0 \pm 8.7$ \\
10 weeks & $33.5 \pm 8.3$ & $35.1 \pm 7.6$ \\
\hline
\end{tabular}

a Data are presented as means \pm standard deviations.

receiveclozapine and 15 were assigned to receive haloperidol. Their sociodemographic and illness characteristics are presented in Table 1.

\section{Study Design}

Patients underwent a 6-week prospective, open-labeled trial of fluphenazine $(20 \mathrm{mg} /$ day) to confirm the presence of neuroleptic partial responsiveness and to establish clinical stability. Patients were than randomly assigned to either clozapine or haloperidol groups during a 10-week double-blind trial. Haloperidol-assigned patients received a fixed dose of double-blind cogentin ( $4 \mathrm{mg} /$ day). Blood was drawn during the last week of fluphenazine treatment (baseline) and after 5 weeks of either clozapine or haloperidol treatment. Pulse rates and blood pressures were obtained at baseline and after 5 weeks of treatment. Daily doses of clozapine and haloperidol were increased progressively in a fixed manner to $400 \mathrm{mg} /$ day and $20 \mathrm{mg} /$ day, respectively, by the 4th treatment week and were then held constant through the 5th week. Thus, blood was drawn at stable doses of comparable potencies of the two drugs.

The night before blood sampling, patients abstained from food and drink except water and reported to the clinic between 8:00 AM and 9:00 AM. An intravenous catheter was inserted into the antecubital fossa and kept patent with a heparin lock. After the subjects had been supine (resting) for 75 minutes, blood samples were drawn.

\section{Assaying Procedure}

Blood for assays of NE, dopa, DOPAC, and DHPG concentrations was collected in heparinized tubes and immediately placed on ice, centrifuged within 30 minutes 
of collection, and the plasma stored at $-70^{\circ} \mathrm{C}$. Plasma catechol levels were assayed simultaneously using liquid chromatography with electrochemical detection, as described previously (Eisenhofer et al. 1986). Briefly, after addition of an internal standard (dihydroxybenylamine) to the plasma, the catechols were extracted by absorption on alumina. After elution from the alumina, they were separated by reverse-phase, ion-pairing liquid chromatography and quantified by the current produced on exposure of the column effluent to a series of oxidizing electrodes and then a reducing electrode. The limits of detection were approximately $10 \mathrm{pg} / \mathrm{ml}$. Blood for assays of cortisol and ACTH concentrations was collected in ethylenediaminetetraacetic acid-containing tubes, immediately placed on ice, centrifuged within 30 minutes of collection, and the plasma was stored at $-70^{\circ} \mathrm{C}$. Cortisol and $\mathrm{ACTH}$ levels were assayed in duplicate by radioimmunoassay (Chrousos et al. 1984). The approximate limit of detection for ACTH was $1 \mathrm{pg} / \mathrm{ml}$ and for cortisol it was $1 \mu \mathrm{g} / \mathrm{dl}$.

\section{Behavioral Assessments}

Positive symptoms were assessed using the sum of the following four Brief Psychiatric Rating Scale (BPRS) (Overall and Gorham 1961) items: hallucinations, conceptual disorganization, suspiciousness, and bizarre thoughts. The sum of the 18-item BPRS (total BPRS scores ranged from 18 to 126) was used as a general measure of symptomatology. The instrument was administered by masters and doctoral level clinicians with extensive experience with schizophrenia. Interrater reliability for the BPRS was 0.87 . These two measures were selected for this study because they were significantly reduced by clozapine in our efficacy study (Breier et al. 1993) and in recent controlled studies (Kane et al. 1988; Pickar et al. 1992). In addition, extrapyramidal symptoms were assessed at baseline and after 10 weeks of treatment, using the Simpson-Angus Scale (scores ranged from 0 to 51)(Simpson and Angus, 1970).

\section{Statistical Analyses}

All plasma indices were furst analyzed in a two-factor multivariate analysis of variance (MANOVA) using Hotelling's statistic, with the factors DRUG (clozapine or haloperidol) and TIME (baseline and 5-week treatment points). If a significant TIME versus DRUG interaction was found, each clozapine versus haloperidol week 5 plasma measure was then analyzed with an analysis of covariance, using baseline plasma levels as the covariate. Effects on physiologic parameters (heart rate, blood pressure) were determined by comparing values at 5 weeks of treatment using baseline (fluphenazine) values as covariates. Five-week treatment minus baseline change values for plasma and physiologic vari- ables and 10-week (endpoint) minus baseline change values for BPRS scores and Simpson-Angus scores were calculated and used in correlative analyses.

\section{RESULTS}

The MANOVA for all neurochemical data revealed significant effects for DRUG $(F=5.6 ; d f=6,18 ; p=$ $.002)$, TIME $(F=4.9 ; d f=6,18 ; p=.004)$, and DRUG versus TIME interaction $(F=5.1 ; d f=6,18 ; p=.003)$.

\section{Norepinephrine Levels}

Plasma NE levels in clozapine-treated patients were almost fivefold greater than those in the same patients treated with fluphenazine and almost fivefold greater than in haloperidol-treated patients (Fig. 1). Haloperidol treatment did not significantly affect plasma NE levels.

\section{Dopa, DOPAC, and DHPG Levels}

Clozapine, in comparison to haloperidol, produced significant elevations in plasma dopa levels and tended to increase plasma DOPAC levels (Table 2). There were, however, no significant differences between clozapine and haloperidol treatment in plasma DHPG levels (Table 2). Changes in dopa levels during clozapine treatment were significantly related to changes in NE levels $(r=.75, p=.008)$. Change in NE was not significantly related to change in DOPAC and DHPG.

\section{Cortisol and ACTH Levels}

There were no significant differences between clozapine and haloperidol for plasma cortisol and ACTH levels (Table 3). Change in plasma NE was not significantly related to changes in cortisol and ACTH.

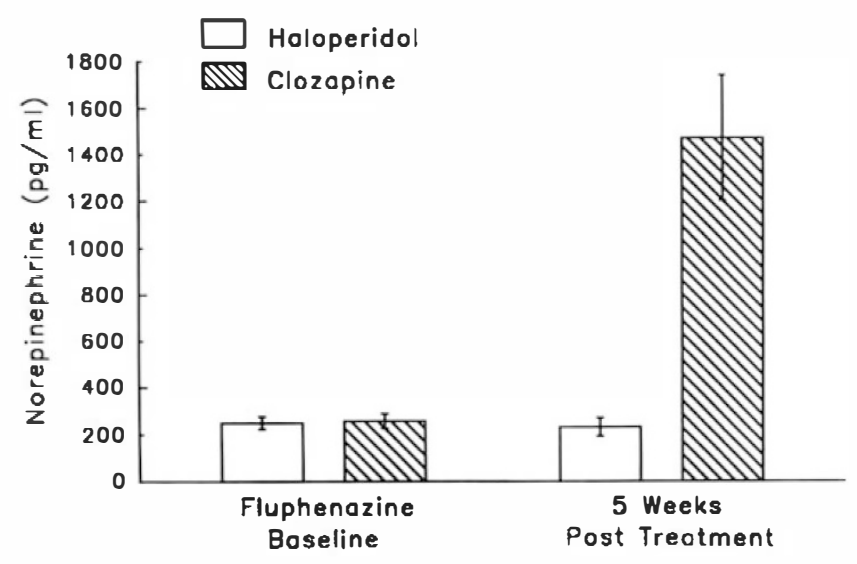

Figure 1. The effects of clozapine $(n=11)$ and haloperidol $(n=15)$ on plasma NE levels (mean $\pm \mathrm{SD}$ ). 
Table 2. The Effects of Clozapine $(n=11)$ and Haloperidol $(n=15)$ on Plasma Catecholaminergic Precursors and Metabolites $(\mathrm{pg} / \mathrm{ml})^{a}$ in Schizophrenic Patients

\begin{tabular}{lcccccc}
\hline \multicolumn{1}{c}{ Drug } & Baseline $^{b}$ & $\begin{array}{c}5 \text { Weeks } \\
\text { Posttreatment }\end{array}$ & \%D & F $^{c}$ & $\boldsymbol{p}$ \\
\hline DOPA & & & & & & \\
Clozapine & $1811.4 \pm 745$ & $2288.7 \pm 1007$ & +26 & & \\
$\quad$ Haloperidol & $1636.9 \pm 518$ & $1633.9 \pm 363$ & 0 & 8.6 & .007 \\
DOPAC & & & & & & \\
$\quad$ Clozapine & $1083.3 \pm 359$ & $1503.4 \pm 795$ & +38 & & \\
Haloperidol & $1087.6 \pm 257$ & $1129.2 \pm 305$ & +4 & 2.8 & .10 \\
DHPG & & & & & & \\
Clozapine & $836.3 \pm 300$ & $768.0 \pm 224$ & -8 & & \\
Haloperidol & $700.3 \pm 126$ & $717.0 \pm 201$ & +2 & .6 & .43 \\
\hline
\end{tabular}

"All levels determined while patients were at rest.

b All patients were stabilized on fluphenazine $20 \mathrm{mg} /$ day.

'Clozapine versus haloperidol week 5 comparisons with baseline levels as covariates.

\section{Heart Rate and Blood Pressure}

There were significant increases in heart rate (beats per minute) produced by clozapine (baseline: $70.2 \pm 11$ and week 5: $101.8 \pm 9$ ), compared with haloperidol (baseline: $69.4 \pm 15$ and week 5: $73.4 \pm 10)(F=62.3 ; d f=$ $1,20 ; p<.0001)$. Systolic blood pressure $(\mathrm{mg} \mathrm{Hg})$ was not significantly different between clozapine (baseline: $119 \pm 15$ and week 5: $120 \pm 15)$ and haloperidol (baseline: $122 \pm 15$ and week $5: 126 \pm 13)(F=1.4 ; d f=1,20$; $p=.23)$. Similarly, diastolic blood pressure was not significantly different between clozapine (baseline: $72 \pm$ 10 and week 5: $76 \pm 9$ ) and haloperidol (baseline: $70 \pm$ 7 and week 5: $76 \pm 7)(F=0.4 ; d f=1,20 ; p=.5)$. There were no significant correlations between change on plasma NE and change in heart rate or systolic or diastolic blood pressure.

\section{Norepinephrine and Symptom Changes}

Changes in plasma NE levels were significantly correlated with clozapine-related changes in BPRS posi-

Table 3. The Effects of Clozapine $(n=11)$ and Haloperidol $(n=15)$ on Plasma ACTH and Cortisol Levels ${ }^{a}$ in Schizophrenic Patients

\begin{tabular}{lccccc}
\hline Drug & Baseline $^{b}$ & $\begin{array}{c}5 \text { Weeks } \\
\text { Posttreatment }\end{array}$ & \%D & F $^{c}$ & $\boldsymbol{p}$ \\
\hline ACTH $(\mathrm{pg} / \mathrm{ml})$ & & & & & \\
Clozapine & $21.7 \pm 20$ & $21.7 \pm 19$ & 0 & & \\
$\begin{array}{l}\text { Haloperidol } \\
\text { Cortisol }(\mu \mathrm{gg} / \mathrm{dl})\end{array}$ & $18.5 \pm 10$ & $17.5 \pm 10$ & -5 & .27 & .60 \\
Clozapine & $9.5 \pm 3$ & $9.6 \pm 4$ & 0 & & \\
Haloperidol & $9.7 \pm 4$ & $10.0 \pm 4$ & 0 & 0 & .99 \\
\hline
\end{tabular}

a All levels determined while patients were supine and at rest.

"All patients were stabilized on fluphenazine $20 \mathrm{mg} /$ day.

'Clozapine versus haloperidol week 5 comparisons with baseline levels as covariates.

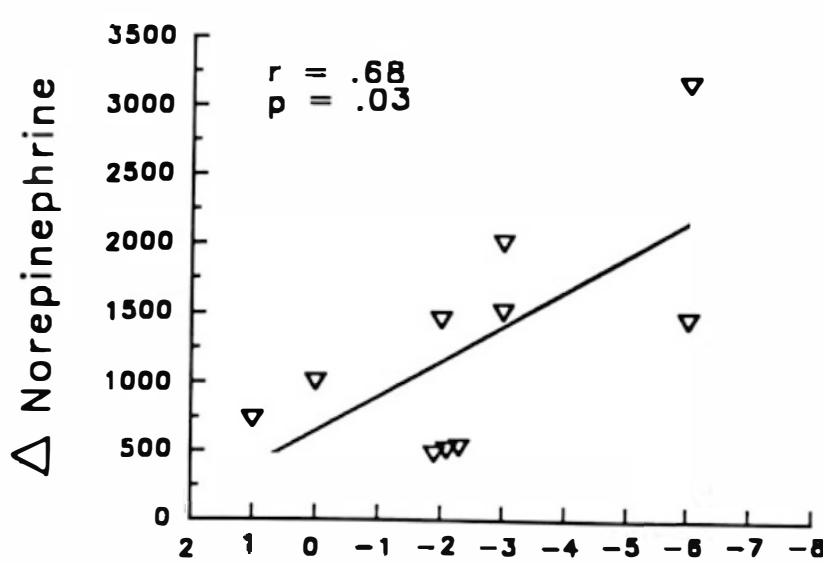

$\triangle$ BPRS Positve Symptoms

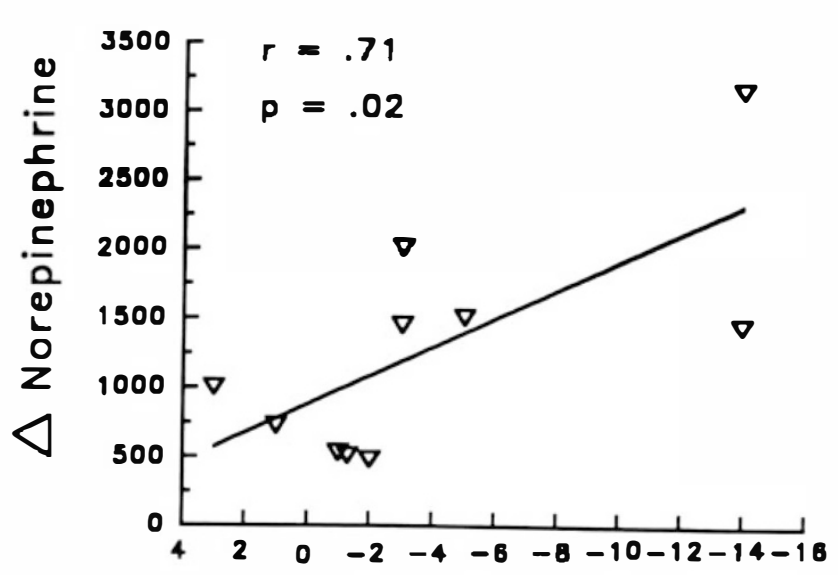

$\triangle$ BPRS Total Symptoms

Figure 2. Relationship between clozapine-induced changes in plasma $\mathrm{NE}(\mathrm{pg} / \mathrm{ml})$ and changes in positive and total BPRS Symptoms.

tive symptom and BPRS total symptom scores (Figure 2). There was no significant relationship between change in NE and change in symptoms during haloperidol treatment. Simpson-Angus scores of extrapyramidal symptoms were low at baseline and after 10 weeks of treatment with clozapine (baseline: $1.5 \pm 1$ and week 10: $1.6 \pm 2.1$ ) or haloperidol (baseline: $1.6 \pm 2$ and week 10: $2.6 \pm 1.8$ ). There was no significant relationship between change in Simpson-Angus scores and change in NE levels.

\section{DISCUSSION}

The results of this study show that clozapine treatment elicits robust increases in plasma NE levels and that these changes are related to the clinical efficacy of clozapine in patients with chronic schizophrenia.

The finding of elevated plasma NE levels agrees 
with previous clinical studies reporting clozapineinduced increases in plasma and CSF NE levels in schizophrenic patients (Lieberman et al. 1991; Pickar et al. 1992; Ackenheil 1989; Sarafoff et al. 1979). These elevations have been interpreted in terms of increased NE release in the brain and periphery; however, increased NE release alone cannot easily explain the lack of concurrent increases in plasma levels of DHPG, the main neuronal metabolite of $\mathrm{NE}$, in the present study, and the lack of concurrent increases in CSF levels of MHPG, a major metabolite of NE in the brain, in the study by Pickar et al. (1992). Additional possible mechanisms of clozapine-induced increases in NE levels are discussed below.

The significant relationship between clozapine's effects on positive and global symptoms and changes in plasma NE levels suggests the possibility that clozapine's superior efficacy profile results from effects on noradrenergic function in the brain. Although most research about catecholamines and schizophrenia has focused on the pathophysiologic role of dopamine, several lines of evidence from postmortem studies (Farley et al. 1978; Bird et al., 1979a, 1979b; Crow et al. 1979; Kleinman et al. 1979) or responses to pharmacologic challenges (Sternberg et al. 1982; Glazer et al. 1987) and CSF and plasma (Breier et al. 1990; van Kammen et al. 1989, 1990; Gomes et al. 1980; Lake et al. 1980; Sternberg et al. 1981; Kemali et al. 1982; Gattaz et al. 1983; Castellani et al. 1982; Naber et al. 1980; Albus et al. 1982) have suggested a noradrenergic mechanism. Circulating NE does not cross the blood-brain barrier (Leimdorfer et al. 1947; Liljedahl and Von Euler 1954; WeilMalherbe et al. 1959), but drugs that affect NE synthesis, release, reuptake, metabolism, or adrenoceptor function in the periphery, and which enter the central nervous system, generally produce the same effects in the brain, accounting for directionally similar changes in CSF and plasma NE levels (Goldstein et al., 1987).

Treatment with haloperidol and fluphenazine was not associated with plasma NE levels above those normally observed in healthy volunteers (Goldstein 1987; Kagedal and Goldstein 1988). The low rate of extrapyramidal symptoms and the lack of correlation between these symptoms and NE levels suggests that the relationship between improvement in positive symptoms and global symptomatology and change in plasma NE is not secondary to the influences of extrapyramidal symptoms.

Clozapine has high affinity for the $\alpha_{1}$-adrenoceptor with three times greater potency at this receptor than haloperidol (Cohen and Lipinski 1986; Richelson and Nelson 1987; Baldessarini and Frankenberg 1991). In addition, clozapine treatment upregulates $\alpha_{1}$-adrenoceptors, with particularly marked effects in forebrain areas (Cohen and Lipinski 1986). In contrast, clozapine has little effect on dopamine $D_{2}$ receptor density, whereas haloperidol and other conventional neurolep- tics upregulate $D_{2}$ receptors (Cohen and Lipinski 1986). One may propose that blockade of $\alpha_{1}$-adrenoceptormediated effects in the brain is the basis for the clinical benefit of clozapine treatment, and that clozapineinduced blockade of $\alpha_{1}$-adrenoceptors may produce secondary increases in NE release.

Clozapine also antagonizes $\alpha_{2}$-adrenoceptors (Souto et al. 1979). Other neuroleptics bind to this receptor as well, although neuroleptics generally bind more avidly to $\alpha_{1}$ - than $\alpha_{2}$-adrenoceptors (Baldessarini et al. $1992)$. In the brain and periphery, $\alpha_{2}$-adrenoceptor blockade increases NE release, probably by interfering with modulation by $\alpha_{2}$-adrenoceptors on noradrenergic cells or terminals.

Combined blockade of $\alpha_{1}$ - than $\alpha_{2}$-adrenoceptors would be expected to produce high plasma NE levels, due to vasodilation-induced reflexive increases in sympathoneural outflow, combined with the above-noted blockade of modulatory $\alpha_{2}$-adrenoceptors on sympathetic nerves. Blockade of $\alpha_{1}$ - and $\alpha_{2}$-adrenoceptors also helps to explain the lack of increase in blood pressure in clozapine-treated patients, despite marked increases in plasma NE levels sufficiently large to evoke vasoconstriction and hypertension in healthy volunteers (Goldstein et al. 1986).

This mechanism of increases in NE levels cannot explain, however, the lack of increase in DHPG levels in the present study, because both reflexive stimulation of sympathetic outflow and blockade of $\alpha_{2}$-adrenoceptors increases reuptake of endogenously released NE. Analogously, clozapine has been reported not to affect CSF MHPG levels, despite significant increases in CSF NE levels (Pickar et al. 1992). The latter finding excludes augmented $O$-methylation as the basis for the lack of increase in DHPG levels.

These unexpected results force consideration of other mechanisms by which clozapine may increase NE concentrations in extracellular fluid in the brain and periphery without concurrent increases in concentrations of its neuronal metabolite. The most straightforward additional mechanism is blockade of NE reuptake. The combination of reuptake blockade and $\alpha_{2}$-adrenoceptor blockade produces marked increases in plasma NE levels in healthy volunteers (Goldstein et al. 1986, 1988). Because blood pressure also increases acutely in this setting, combined reuptake blockade and $\alpha_{2}$-adrenoceptor blockade would not account for the hemodynamic data. The combination of high plasma NE levels, the absence of changes in DHPG levels, and the absence of hypertension during clozapine treatment therefore seem to require a complex mechanism that includes blockade of both subtypes of $\alpha$-adrenoceptors and blockade of the NE transporter. We are unaware of research findings testing the latter putative effect of clozapine. The increases in plasma DOPA and DOPAC levels are consistent with increased catecholamine biosynthesis in sympathetic nerves, to match increases in noradren- 
ergic turnover. Analogous changes in DOPA and DOPAC levels have been reported in noradrenergic centers in the brain in animals undergoing clozapine treatment (Baldessarini et al. 1992). It will be important to examine the timecourse of clozapine's effects on noradrenergic function to determine if data gleaned from acute dosing studies apply to chronic treatment conditions.

The failure of clozapine to change plasma ACTH and cortisol levels supports the contention that the elevations in plasma NE levels are not secondary to generalized arousal or distress. Previous clinical studies have reported that chronic clozapine treatment decreases plasma cortisol levels (Pickar et al. 1992; Meltzer 1989). It is possible that reductions in cortisol previously observed were secondary to clozapine's effects on reducing stress and arousal, compared with levels in the untreated control condition. Because our subjects were stable outpatients and did not participate in neuroleptic washout (which may increase arousal, activation and stress) prior to clozapine treatment, they would have been less likely to experience stress-reducing effects from clozapine.

In summary, clozapine treatment markedly increases plasma NE levels, with the increases related to clinical effects of the drug. The mechanism of noradrenergic activation appears to be complex, possibly involving a combination of adrenoceptor blockade and blockade of the NE transporter. The findings generally lead one to reconsider the role of endogenous NE in the pathophysiology of schizophrenia, with central noradrenergic systems a potential new target of antipsychotic drug action.

\section{REFERENCES}

Ackenheil M (1989): Clozapine: pharmacokinetic investigation and biochemical effects: Psychopharmacology 99: S32-S37

Albus M, Engel RR, Muller F, et al (1982): Experimental stress situations and the state of autonomic arousal in schizophrenic and depressive patients. Int Pharmacopsychiatr 17:129-135

American Psychiatric Association (1987): Diagnostic and Statistical Manual of Mental Disorders, 3rd Edition, Revised. Washington DC, American Psychiatric Press

Baldessarini RJ, Frankenburg FR (1991): Clozapine: A novel antipsychotic agent. N Engl J Med 324:646-654

Baldessarini RJ, Huston-Lyons D, Campbell A, Marsh E, Cohen BM (1992): Do central antiadrenergic actions contribute to the atypical properties of clozapine? Br J Psychiatry $160: 12-16$

Bird ED, Spokes EGS, Iversen LL (1979a): Increased dopamine concentration in limbic areas of brain from patients dying with schizophrenia. Brain 102:347-360

Bird ED, Spokes EGS, Iversen LL (1979b): Brain norepinephrine and dopamine in schizophrenia. Science 204:93-94
Breier A, Buchanan RW, Kirkpatrick B, Davis OR, Irish D, Summerfelt A, Carpenter WT Jr (1993): Clozapine in schizophrenic outpatients: effects on positive and negative symptoms. Am J Psychiatry, in press

Breier A, Wolkowitz OM, Roy A, Potter WZ, Pickar D (1990): Plasma norepinephrine in chronic schizophrenia. Am J Psychiatry 147:1467-1470

Castellani S, Ziegler MG, van Kammen DP, et al (1982): Plasma norepinephrine and dopamine-beta-hydroxylase activity in schizophrenia. Arch Gen Psychiatry 39:11451149

Chrousos GP, Schulte HM, Oldfield EH, et al (1984): The corticotropin-releasing factor stimulation test. N Engl Med J 310:622

Cohen BM, Lipinski JF (1986): In vivo potencies of antipsychotic drugs in blocking alpha 1 noradrenergic and dopamine D2 receptors: Implications for drug mechanisms of action. Life Sci 39:2571-2580

Crow TJ, Baker HF, Cross AJ, Joseph MH, et al (1979): Monoamine mechanisms in chronic schizophrenia: Post-mortem neurochemical findings. Br J Psychiatry 134:249-256

Eisenhofer G, Goldstein DS, Stull R, et al (1986): Simultaneous liquid chromatographic determination of 3,4-dihydroxyphenylglycol, catecholamines, and 3,4-dihydroxyphenylalanine and their responses to inhibition of monoamine oxidase. Clin Chem 32:2030

Farley IJ, Price KS, McCullough E (1978): Norepinephrine in chronic paranoid schizophrenia: Above-normal levels in limbic forebrain. Science 200:456-458

Gattaz WF, Riederer P, Reynolds GP, et al (1983): Dopamine and noradrenaline in the cerebrospinal fluid of schizophrenic patients. Psychiatry Res 8:243-250

Glazer WM, Charney DS, Heninger GR (1987): Noradrenergic function in schizophrenia. Arch Gen Psychiatry 44:898-904

Goldstein DS (1987): Catecholamines in plasma and cerebrospinal fluid: Sources and meanings. In Buckley JP, FarrarioCM (eds), Brain Peptides and Catecholamines in Cardiovascular Regulation. New York, Raven Press, pp 15-25

Goldstein DS, Zimlichman R, Stull R, et al (1986): Estimation of intrasynaptic norepinephrine concentrations in humans. Hypertension 8:471-475

Goldstein DS, Zimlichman R, Kelly GB, et al (1987): Effect of ganglion blockade on cerebrospinal fluid norepinephrine. J Neurochem 49:1484-1490

Goldstein DS, Eisenhofer G, Stull R, et al (1988): Plasma dihydroxyphenylglucol and the intraneuronal disposition of norepinephrine in humans. J Clin Invest 81:213-220

Gomes UCR, Shanley BC, Potgieter L, et al (1980): Noradrenergic overactivity in chronic schizophrenia: Evidence based on cerebrospinal fluid noradrenergic and cyclic nucleotide concentrations. Br J Psychiatry 137:346-351

Kågedal B (1988): Catecholamines and their metabolites. J Chromatogr 429:177-233

Kane J, Honigfeld G, Singer J, Meltzer H (1988): Clozapine for the treatment-resistant schizophrenic: a double-blind comparison with chlorpromazine. Arch Gen Psychiatry 45:789-796 
Kemali D, Del Vecchio M, Maj M (1982): Increased noradrenaline levels in CSF and plasma of schizophrenic patients. Biol Psychiatry 17:711-717

Kleinman JE, Bridge P, Karoum F, et al (1979): Catecholamines and metabolites in the brains of psychotics and normals: Post-mortem studies. In Usdin E, Kopin IJ, Barchas J (eds), Catecholamines: Basic and Clinical Frontiers, Vol 1. Elmsford, New York, Pergamon Press, pp 1845-1847

Kopin IJ (1985): Catecholamine metabolism: Basic aspects and clinical significance. Pharmacol Rev 37:333-364

Lake CR, Sternberg D, van Kammen DP, et al (1980): Schizophrenia: Elevated cerebrospinal fluid norepinephrine. Science 207:331-333

Leimdorfer A, Arana R, Hack M (1947): Hyperglycemia induced by action of adrenalin on central nervous system. Am J Physiol 150:588-595

Lieberman J, Johns C, Pollack S Masiar S, Bookstein P, Cooper T, Iadorola M, Kane J (1991): Biochemical effects of clozapine in cerebrospinal fluid of patients with schizophrenia. In Tamminga CA, Schulz SC (eds), Schizophrenia Research, Vol 1. New York, Raven Press, pp 341-349

Liljedahl SO, Von Euler US (1954): Elimination of noradrenergic from spinal fluid. Acta Chir Scand 108:163-169

Meltzer HY, Bernett S, Bastani B, Ramirez LF (1990): Effects of six months of clozapine treatment on the quality of life of chronic schizophrenic patients. Hosp Commun Psychiatry 41:892-897

Meltzer HY (1989): Clinical studies on the mechanism of action of clozapine: The dopamine-serotonin hypothesis of schizophrenia. Psychopharmacology 99:S18-S27

Naber D, Finkbeiner C, Fischer B, et al (1980): Effect of longterm neuroleptic treatment of prolactin and norepinephrine levels in serum of chronic schizophrenics: Relations to psychopathology and extrapyramidal symptoms. Neuropsychobiology 6:181-189

Overall JE, Gorham DE (1961): The Brief Psychiatric Rating Scale. Psychol Rep 10:799-812

Pickar D, Owen RR, Litman RE, Konicki E, Gutierrez R, Rapaport MH (1992): Clinical and biologic response to clozapine in patients with schizophrenia. Crossover comparison with fluphenazine. Arch Gen Psychiatry 49: 345-353

Ramirez OA, Wang RY (1986): Locus coeruleus norepineph- rine-containing neurons: Effects produced by acute and subchronic treatment with antipsychotic drugs and amphetamine. Brain Res 362:165-170

Richelson E, Nelson A (1984): Antagonism by neuroleptics of neurotransmitter receptors of normal brain in vitro. Eur J Pharmacol 103:197-204

Roy A, Pickar D, De Jong J, et al (1988): Norepinephrine and its metabolites in cerebrospinal fluid, plasma, and urine. Arch Gen Psychiatry 45:849-857

Sarafoff M, Davis L, Ruther E (1979): Clozapine induced increase of human plasma norepinephrine. J Neural Transm 46:175-180

Simpson G, Angus LSW (1970): A rating scale for extrapyramidal side effects. Acta Psychiatr Scand Suppl 212:9-11

Souto M, Mouti JM, Altier H (1979): Effects of clozapine on the activity of central dopaminergic and noradrenergic neurons. Pharmacol Biochem Behav 10:5-9

Spitzer RL, Williams JBW, Gibbon N, et al (1989): Structured Clinical Interview for DSM-III-R. New York, New York State Psychiatric Institute, Biometrics Research

Sternberg DE, Charney DS, Heninger GR, et al (1982): Impaired presynaptic regulation of norepinephrine in schizophrenia. Arch Gen Psychiatry 39:285-289

Sternberg DE, van Kammen DP, Lake CR, et al (1981): The effect of pimozide on CSF norepinephrine in schizophrenia. Am J Psychiatry 138:1045-1051

van Kammen DP, Peters J, Yao J, et al (1990): Norepinephrine in acute exacerbations of chronic schizophrenia. Arch Gen Psychiatry 47:161-168

van Kammen DP, Peters J, van Kammen WB, et al (1989): CSF norepinephrine in schizophrenia is elevated prior to relapse after haloperidol withdrawal. Biol Psychiatry 26:176-188

Van Tol HHM, Bunzow JR, Guan H-C, et al (1991): Cloning of the gene for a human dopamine $\mathrm{D}_{4}$ receptor with high affinity for the antipsychotic clozapine. Nature 350:610614

Weil-Malherbe H, Axelrod J, Tomchick R (1959): Blood-brain barrier for adrenaline. Science 129:1226-1227

Ziegler MG, Lake CR, Wood JH, et al (1977): Relationship between norepinephrine in blood and cerebrospinal fluid in the presence of a blood-cerebrospinal fluid barrier for norepinephrine. J Neurochem 28:677-679 